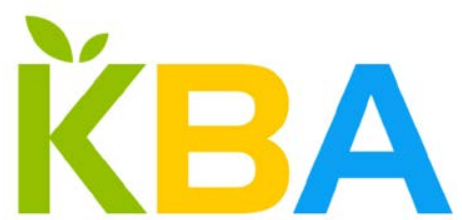

KEY BIODIVERSITY AREAS

\title{
Guidelines on Business and KBAs: Managing Risk to Biodiversity
}

CONSERVATION INTERNATIONAL

\section{extor:} 1.1. 200 tê.

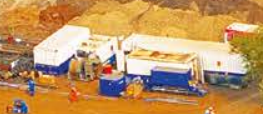

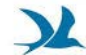 \\ Birdlife \\ Burcantrowe}

CRITICAL $\mid \begin{gathered}\text { ECOSYSTEM } \\ \text { PARTNERSHIP FUND }\end{gathered}$

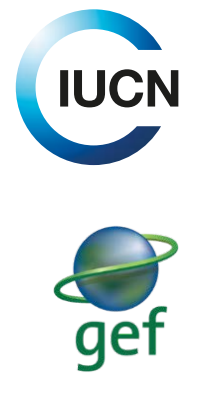

rasa

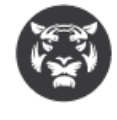

GLOBAL CONSERVATION

A Natureserve 



\section{Guidelines on Business and KBAs: Managing Risk to Biodiversity}


The designation of geographical entities in this document, and the presentation of the material, do not imply the expression of any opinion whatsoever on the part of IUCN or other participating organisations concerning the legal status of any country, territory, or area, or of its authorities, or concerning the delimitation of its frontiers or boundaries.

The views expressed in this document do not necessarily reflect those of IUCN or other participating organisations.

The development of this document was made possible with the generous support of The Tiffany \& Co. Foundation.

Published by: $\quad$ IUCN, Gland, Switzerland in collaboration with KBA partners

Copyright: $\quad$ C 2018 IUCN, International Union for Conservation of Nature and Natural Resources

Reproduction of this publication for educational or other non-commercial purposes is authorised without prior written permission from the copyright holder, provided the source is fully acknowledged.

Reproduction of this publication for resale or other commercial purposes is prohibited without prior written permission of the copyright holder.

Citation:

The KBA Partnership (2018) Guidelines on Business and KBAs: Managing Risk to Biodiversity. Gland: IUCN. 24pp, 2018

ISBN:

$978-2-8317-1894-1$

DOI:

https://doi.org/10.2305/IUCN.CH.2018.05.en

Cover photo:

Oil drilling in the Queen Elizabeth National Park, Uganda (C) A.Plumptre/WCS

Layout by:

Imre Sebestyén, jr / UNITgraphics

Available from:

IUCN (International Union for Conservation of Nature)

Business and Biodiversity Programme

Rue Mauverney 28

1196 Gland

Switzerland

Tel +41229990000

Fax +41229990002

biobiz@iucn.org

www.iucn.org/resources/publications

www.keybiodiversityareas.org 


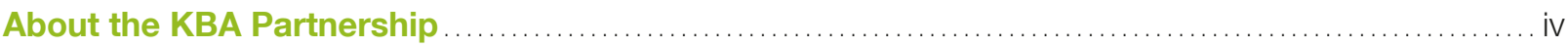

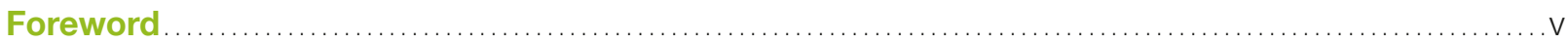

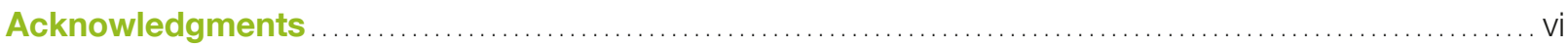

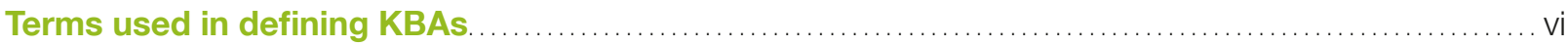

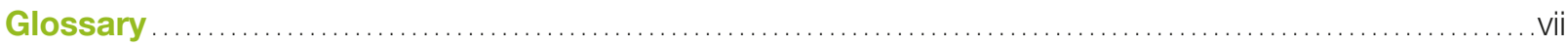

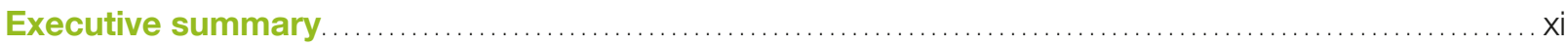

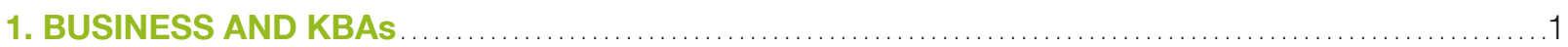

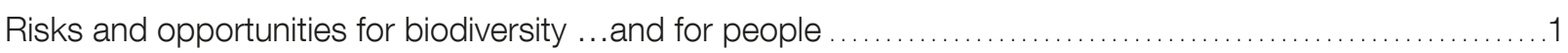

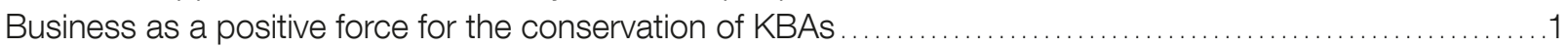

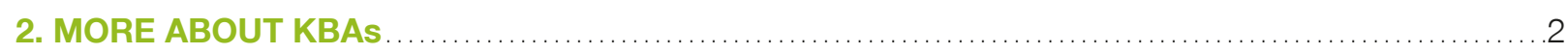

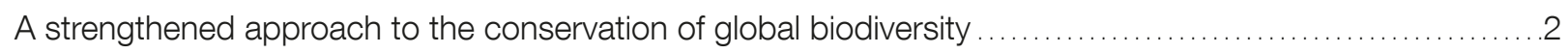

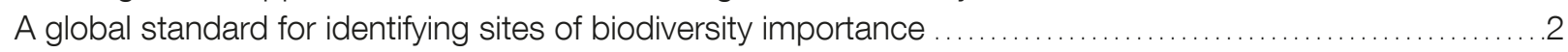

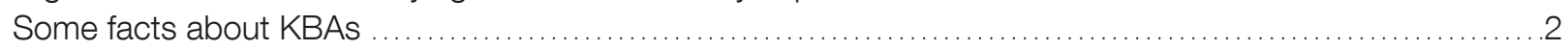

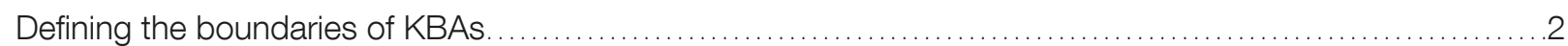

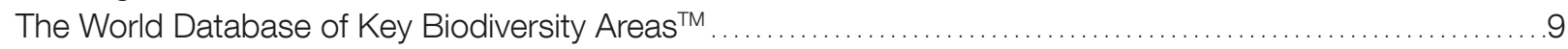

Key Biodiversity Areas, protected areas, and conservation priorities. .................................

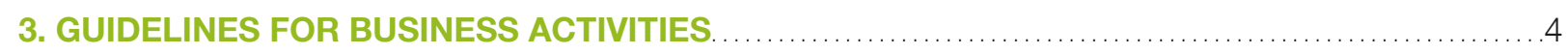

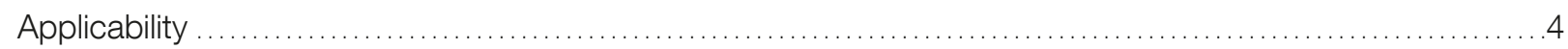

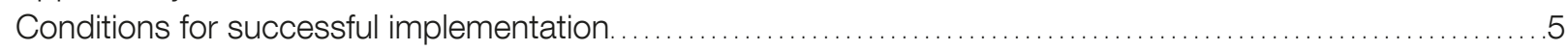

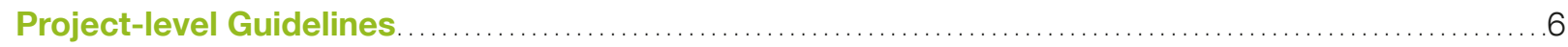

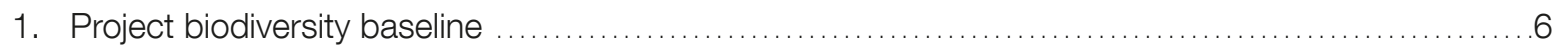

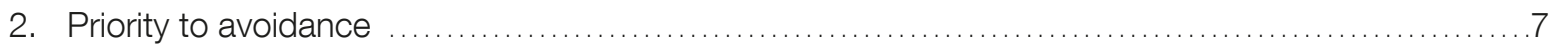

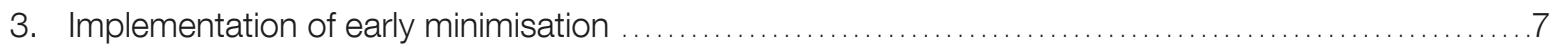

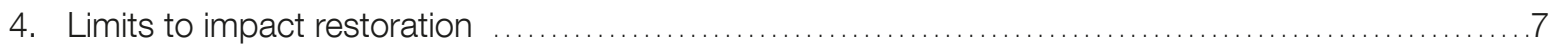

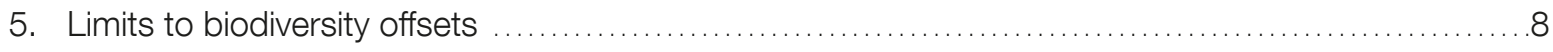

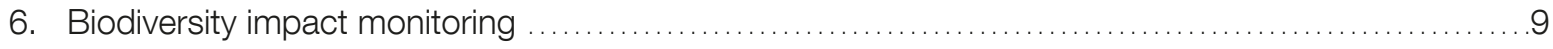

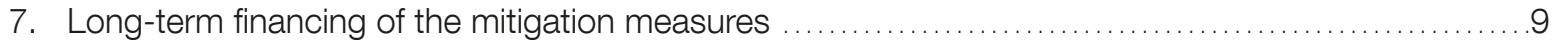

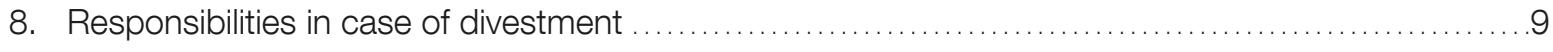

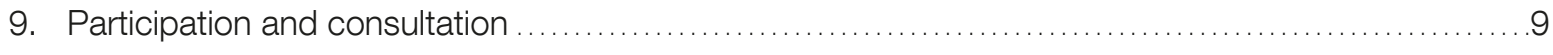

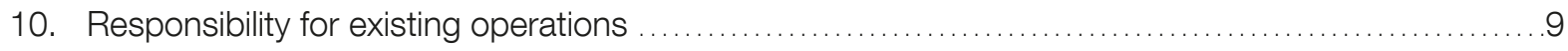

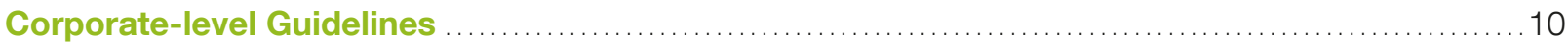

11. Reporting on KBAs as part of the company's environmental performance ....................... 10

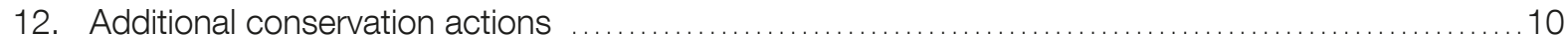

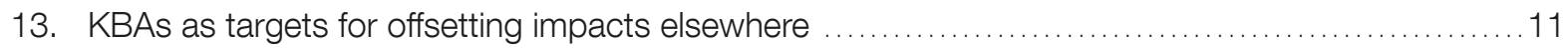

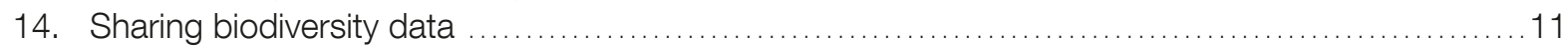

15. Compliance with certification schemes and financial institutions' safeguard policies..............11

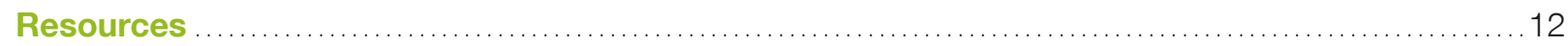




\section{About the KBA Partnership}

The Key Biodiversity Area (KBA) Partnership is made up of 12 of the world's leading international nature conservation organizations. Together, they will mobilise the expertise, experience and resources of the partner organizations to:

- Identify, map, document and monitor KBAs worldwide

- Promote targeted conservation actions in KBAs and

- Inform and influence public policy and private sector decision-making to safeguard KBAs and ensure their effective conservation.

The KBA Partnership comprises 12 partners:

BirdLife International www.birdlife.org

IUCN www.iucn.org

Amphibian Survival Alliance www.amphibians.org

Conservation International www.conservation.org

Critical Ecosystem Partnership Fund www.cepf.net

Global Environment Facility www.thegef.org

Global Wildllife Conservation globalwildlife.org

NatureServe www.natureserve.org

Rainforest Trust www.rainforesttrust.org

Royal Society for the Protection of Birds www.rspb.org.uk

WWF www.panda.org

Wildlife Conservation Society www.wcs.org

BirdLife International manages the World Database of Key Biodiversity Areas on behalf of the KBA Partnership.

The KBA Partners stand ready to provide support to any business interested in operating in accordance with these Guidelines, in particular through the KBA Consultative Forum. The KBA Consultative Forum consists of a wide range of end-users of the KBA Data who provide input and advice to the KBA Committee on the dissemination and use of KBA data, management decisions, marketing, funding, etc. of the KBA Programme, and who in turn are informed about progress and plans in the implementation of the KBA Programme. End users include, among others, national governments, multilateral environmental agreements (e.g. Convention on Biological Diversity, Ramsar Convention), international financing institutions, private sector companies, intergovernmental agencies, indigenous peoples organizations and non-governmental organizations.

The primary role of the KBA Consultative Forum is to communicate needs and challenges in the use and application of KBA Data to the KBA Committee, and conversely to be informed by the KBA Committee about decisions, progress and plans regarding the implementation of the KBA Programme.

The Consultative Forum is established by the KBA Committee. The current Co-Chairs of the Consultative Forum are: Olivier Langrand, Critical Ecosystems Partnership Fund, Daniela Raik, Conservation International (chair.consultative.forum@keybiodiversityareas.org).

Main document: Terms of Reference of the KBA Consultative Forum 


\section{FOREWORD}

The destruction, degradation, and overexploitation of natural habitats is leading to a rapid loss of biodiversity, jeopardising the ecosystem services upon which human society depends. To halt this trend, it is vital to know which places on the planet make particularly significant contributions to the global persistence of biodiversity, so that we can facilitate management of these areas and ensure that they continue to support their important species, ecosystems, and genetic diversity.

Responding to this need, IUCN's WCPA-SSC Joint Task Force on Biodiversity and Protected Areas led a multi-year consultation process to develop a set of globally standardised, quantitative criteria for the identification of Key Biodiversity Areas (KBAs) worldwide. A Global Standard for the Identification of Key Biodiversity Areas provides an overarching common framework for the identification of sites that contribute significantly to the global persistence of biodiversity. Since its launch at the IUCN World Conservation Congress in 2016, the KBA Standard has been an important step forward for global biodiversity conservation. Building on this effort, 12 of the world's leading nature conservation organisations ${ }^{2}$ have launched an ambitious new Key Biodiversity Areas Partnership, to map, monitor, and conserve the most important places for life on earth.

The KBA Standard also offers a platform to reach out to the many key actors who have the ability to both positively and negatively affect biodiversity conservation, in particular the business community. Given that some business activities can have a significant role in driving biodiversity loss - for example through land-use changes, pollution, or introduction of invasive species - stemming the global biodiversity crisis requires mainstreaming best practices for mitigating biodiversity risks and impacts into all facets of business operations.

The KBA Partners have embraced this challenge. For the past two years, we have worked to distil key guidelines for supporting the effective management of biodiversity risks to KBAs that may arise from business activities. The resulting 15 Guidelines on Business and KBAs reflect a consensus among the KBA Partners on how to address challenging topics, such as avoidance of impacts, biodiversity offsets in KBAs, financial guarantees, corporate reporting, and other critical issues. These Guidelines are designed to help businesses, certification scheme operators, financial institutions, civil society organisations, and public authorities develop policies and standards to manage biodiversity risks in KBAs.

The process of developing these Guidelines has been at times quite challenging, as there are different values at stake and a wide range of approaches to responsible land use. However, despite these differences, we are united by our recognition of the urgency of changing the way we relate to nature.

Our hope is that companies will embed these Guidelines in their biodiversity policies, voluntary sustainability standards, financial safeguards, and regulations, thus creating a level playing field among businesses and leading to more effective conservation of Key Biodiversity Areas around the world.

January 2018

The KBA Partners 


\section{Acknowledgments}

This document has been prepared by IUCN, based on the guidance and input provided by representatives of the KBA Partners. This document also builds on the input provided by the participants to the End Users Consultation workshop (held in Gland, Switzerland, 4-5 July 2016) and by the organisations that submitted comments during the public consultation period (2 December 2016-17 March 2017).

The Tiffany \& Co. Foundation supported the development of these guidelines as part of its Responsible Mining Program. The Foundation values collaboration from civil society to help businesses, certification systems, governments and others define and implement more responsible practices in order to protect Key Biodiversity Areas worldwide.

These guidelines are recommended minimum requirements for business operations having direct, indirect, and cumulative impacts on a Key Biodiversity Area, unless the national or local law is more stringent, in which case the law shall prevail.

The KBA Partners will collect feedback on this first version of the Guidelines and organise a revision within 5 years.

\section{Terms used in defining KBAs}

\section{Key Biodiversity Areas (KBA) are sites contributing significantly to the global persistence of biodiversity.}

Biodiversity: Biodiversity is 'the variability among living organisms from all sources including, inter alia, terrestrial, marine and other aquatic ecosystems and the ecological complexes of which they are part; this includes diversity within species, between species and of ecosystems', according to the Convention on Biological Diversity (CBD) (UN 1992).

Contributing/Contribution: The contribution of a site to the global persistence of biodiversity depends on the global distribution and the abundance of the biodiversity elements for which the site is important. Sites holding biodiversity elements that are globally restricted, or at risk of disappearing, make high contributions to the persistence of those elements. The global persistence of a biodiversity element occurring at any given KBA, unless it is entirely confined to the site, depends not only on the fate of the site itself but also on that of other sites and of the land-/seascapes where it occurs.

Global: Global implies that the contributions of a site to the persistence of a given biodiversity element are measured in relation to its worldwide population size or extent.

Persistence: Persistence of a biodiversity element means that its loss (e.g. species extinction, ecosystem collapse) or decline (e.g. of numbers of mature individuals of a species, ecosystem extent and condition) is avoided, both now and into the foreseeable future.

Significantly/Significant: Significant means that an outstanding proportion of a biodiversity element (e.g. species population size or ecosystem extent) occurs at the site, as defined by a quantitative threshold.

Site: A geographical area on land and/or in water, with defined ecological, physical, administrative, or management boundaries, that is actually or potentially manageable as a single unit (e.g. a protected area or other managed conservation unit). For this reason, large-scale biogeographic regions such as ecoregions, Endemic Bird Areas and Biodiversity Hotspots, and land-/seascapes containing multiple management units, are not considered to be sites. In the context of KBAs, 'site' and 'area' are used interchangeably. 
Additional Conservation Actions: A broad range of activities that are intended to benefit biodiversity, where the effects or outcomes can be difficult to quantify. (Biodiversity A to Z )

Avoidance: Measures taken to prevent impacts from occurring in the first place, for instance by changing or adjusting the development project's location and/or the scope, nature, and timing of its activities. (Glossary (2012), BBOP)

Baseline: A description of existing conditions to provide a starting point (e.g. pre-project condition of biodiversity) against which comparisons can be made (e.g. post-impact condition of biodiversity), allowing the change to be quantified. (Glossary (2012), BBOP)

Biological diversity: The variability among living organisms from all sources including, inter alia, terrestrial, marine and other aquatic ecosystems and the ecological complexes of which they are part; this includes diversity within species, between species and of ecosystems. (Convention on Biological Diversity, 1992)

Biological resources: The genetic resources, organisms or parts thereof, populations, or any other biotic component of ecosystems with actual or potential use or value for humanity. (Convention on Biological Diversity, 1992)

Biodiversity element: Genes, species, or ecosystems, as used by the Convention on Biological Diversity (CBD) definition of biodiversity. (A Global Standard for the Identification of Key Biodiversity Areas (2016), IUCN)

Biodiversity loss: Biodiversity loss is usually observed as one or all of: (1) reduced area occupied by populations, species, and community types, (2) loss of populations and the genetic diversity they contribute to the whole species, and (3) reduced abundance (of populations and species) or condition (of communities and ecosystems). The likelihood of any biodiversity component persisting (the persistence probability) in the long term declines with lower abundance and genetic diversity and reduced habitat area. (Glossary (2012). BBOP)

Biodiversity offsets: Biodiversity offsets are measurable conservation outcomes resulting from actions designed to compensate for significant residual adverse biodiversity impacts arising from project development after appropriate mitigation measures have been taken. The goal of biodiversity offsets is to achieve no net loss and preferably a net gain of biodiversity on the ground with respect to species composition, habitat structure, and ecosystem function, and people's use and cultural values associated with biodiversity. (Glossary (2012). $\mathrm{BBOP}$

Conservation outcome: A conservation outcome is the result of a conservation intervention aimed at addressing direct threats to biodiversity or their underlying socio-political, cultural, and/or economic causes. Conservation outcomes are typically in the form of: (a) extinctions avoided (i.e. outcomes that lead to improvements in a species' national or global threat status); (b) sites protected (i.e. outcomes that lead to designation of a site as a formal or informal protection area, or to improvement in the management effectiveness of an existing protected area); and (c) corridors created (i.e. outcomes that lead to the creation of interconnected networks of sites at the landscape scale, capable of maintaining intact biotic assemblages and natural processes, and, thereby, enhancing the long-term viability of natural ecosystems). Conservation outcomes would also include any other intervention that leads to conservation gains. (Glossary (2012), BBOP)

Critical habitat: A number of lending institutions have recently defined 'critical habitat', accompanied by conditions for clients whose projects may impact upon it. Common themes mentioned by these definitions include threatened species, endemic or geographically restricted species, congregations of migratory and other species, assemblages that support key processes or services, and biodiversity of social, economic, or cultural value. Examples of definitions include the following: 
1. Critical habitats are areas with high biodiversity value, including (i) habitat of significant importance to Critically Endangered and/or Endangered species; (ii) habitat of significant importance to endemic and/or restricted-range species; (iii) habitat supporting globally significant concentrations of migratory species and/or congregatory species; (iv) highly threatened and/or unique ecosystems; and/or (v) areas associated with key evolutionary processes. This definition adds in a footnote that 'Critically Endangered and/or Endangered species' are as listed on the International Union for the Conservation of Nature (IUCN) Red List of Threatened Species. The determination of critical habitat based on other listings is as follows: (i) If the species is listed nationally/regionally as critically endangered or endangered, in countries that have adhered to IUCN guidance, the critical habitat determination will be made on a project-by-project basis in consultation with competent professionals; and (ii) In instances where nationally or regionally listed species' categorisations do not correspond well to those of IUCN (e.g., some countries more generally list species as 'protected' or 'restricted'), an assessment will be conducted to determine the rationale and purpose of the listing. In this case, the critical habitat determination will be based on such an assessment. (IFC Performance Standard 6. January 2012)

2. Irrespective of whether it is natural or modified, some habitat may be considered to be critical by virtue of (i) its high biodiversity value, (ii) its importance to the survival of endangered or critically endangered species, (iii) its importance to endemic or geographically restricted species and sub-species, (iv) its importance to migratory or congregatory species, (v) its role in supporting assemblages of species associated with key evolutionary processes, (vi) its role in supporting biodiversity of significant social, economical, or cultural importance to local communities, or (vii) its importance to species that are vital to the ecosystem as a whole (keystone species). (EBRD Environmental and Social Policy, 12 May 2008)

Cumulative impact: The total impact arising from the project (under the control of the developer); other activities (that may be under the control of others, including other developers, local communities, government), and other background pressures and trends which may be unregulated. The project's impact is therefore one part of the total cumulative impact on the environment. The analysis of a project's incremental impacts combined with the effects of other projects can often give a more accurate understanding of the likely results of the project's presence than just considering its impacts in isolation. (Glossary (2012), BBOP)

Direct impact: An outcome directly attributable to a defined action or project activity (often also called primary impact). (Glossary (2012), BBOP)

Ecosystem: A dynamic complex of plant, animal and micro-organism communities and their non-living environment interacting as a functional unit. (Convention on Biological Diversity, 1992)

Ecosystem services: The benefits people obtain from ecosystems. These include provisioning services such as food, water, timber, and fibre; regulating services that affect climate, floods, disease, wastes, and water quality; cultural services that provide recreational, aesthetic, and spiritual benefits; and supporting services such as soil formation, photosynthesis, and nutrient cycling. (Glossary (2012), BBOP)

Go/No Go: The decision as to whether a project should proceed or not, usually taken by regulators and/or companies prior to project inception and based on a complex dialogue involving a range of stakeholders and concerns, of which impacts on biodiversity are only one. A 'No Go' decision may be taken because a project is not suitable for reasons other than its impacts on biodiversity. Equally, a project with a very significant, nonoffsetable impact on biodiversity may still result in a 'Go' decision based on other benefits (such as needed infrastructure, jobs, or development), considered to outweigh its environmental costs. (Glossary (2012), BBOP)

Habitat: The place or type of site where an organism or population naturally occurs. (Convention on Biological Diversity, 1992)

High Conservation Value area: High Conservation Value areas are critical areas in a landscape which need to be appropriately managed in order to maintain or enhance High Conservation Values (HCVs). There are six main types of HCV area, based on the definition originally developed by the Forest Stewardship Council for certification of forest ecosystems. (HCV Resource Network Charter (2015), HCV Resource Network) 
Indirect impacts: Indirect impacts (sometimes called secondary impacts or induced impacts), are impacts triggered in response to the presence of the project, rather than being directly caused by the project's own operations. For instance, the presence of a project such as an oil and gas facility may lead to an increased local workforce and associated increases in demand for food. This may have knock-on effects on biodiversity, for example due to increased land conversion for farming or increased levels of hunting. Indirect impacts may reach outside project boundaries and may begin before or extend beyond a project's lifecycle. Indirect impacts should be predicted with a thorough Environmental and Social Impact Assessment (ESIA) process that includes biodiversity issues and explicitly links environmental and social issues, although there is a risk that the potential for such impacts may not be identified until later in the project cycle. As a general rule, indirect impacts are more difficult to map and quantify than direct impacts. (Glossary (2012), BBOP)

Like-for-like or better: A common approach to biodiversity offsets is to require conservation (through the biodiversity offset) of the same type of biodiversity as that affected by the project. This is known as 'like-for-like'. This is sometimes modified to 'like-for-like or better', in which the offset conserves components of biodiversity that are a higher conservation priority (for example because they are more irreplaceable and vulnerable) than those affected by the development project for which the offset is envisaged. This is also known as 'trading up'. (Glossary (2012), BBOP)

Monitoring: Activities undertaken after the decision is made to adopt the plan, programme, or project to examine its implementation. For example, monitoring to examine whether the significant environmental effects occur as predicted or to establish whether mitigation measures are implemented. (Glossary (2012), BBOP)

No net loss/Net gain: A target for a development project in which the impacts on biodiversity caused by the project are balanced or outweighed by measures taken to avoid and minimise the project's impacts, to undertake on-site restoration, and finally to offset the residual impacts, so that no loss remains. Where the gain exceeds the loss, the term 'net gain' may be used instead of no net loss. No net loss (or net gain) of biodiversity is a policy goal in several countries, and is also the goal of voluntary biodiversity offsets. (Glossary (2012), BBOP)

Protected area: A protected area is a clearly defined geographical space, recognised, dedicated, and managed, through legal or other effective means, to achieve the long-term conservation of nature with associated ecosystem services and cultural values. (Guidelines for Appling Protected Areas Management Categories (2008), IUCN)

Residual impact: The remaining adverse impact on biodiversity after appropriate avoidance, minimisation, and rehabilitation measures have been taken according to the mitigation hierarchy. (Glossary (2012), BBOP)

Restoration: The process of assisting the recovery of an area or ecosystem that has been degraded, damaged, or destroyed. The aim of ecological restoration is to re-establish the ecosystem's composition, structure, and function, usually bringing it back to its original (pre-disturbance) state or to a healthy state close to the original. An ecosystem is restored when it contains sufficient biotic and abiotic resources to sustain itself structurally and functionally and can continue its development without further assistance or subsidy. It will demonstrate resilience to normal ranges of environmental stress and disturbance and interact with contiguous ecosystems in terms of biotic and abiotic flows and cultural interactions. Ecological restoration strives to alter the biota and physical conditions at a site, and is frequently confused with rehabilitation. While restoration aims to return an ecosystem to a former natural condition, rehabilitation implies putting the landscape to a new or altered use to serve a particular human purpose. Activities such as ecological engineering and various kinds of resource management, including wildlife, fisheries and range management, agroforestry, and forestry may qualify as ecological restoration if they satisfy the criteria set out by the Society for Ecological Restoration. This Society lists nine attributes as a basis for determining when restoration has been accomplished. (Society for Ecological Restoration)

Thresholds: Numeric or percentage minima which determine whether the presence of a biodiversity element at a site is significant enough for the site to be considered a KBA under a given criterion or sub-criterion. (A Global Standard for the Identification of Key Biodiversity Areas (2016), IUCN) 
Trading up: Conserving, through an offset, components of biodiversity that are a higher conservation priority (for example because they are more irreplaceable and vulnerable) than those affected by the development project for which the offset is envisaged. (Glossary (2012), BBOP)

Trigger: A biodiversity element (e.g. species or ecosystem) by which at least one KBA criterion and associated threshold is met. (A Global Standard for the Identification of Key Biodiversity Areas (2016). IUCN) 


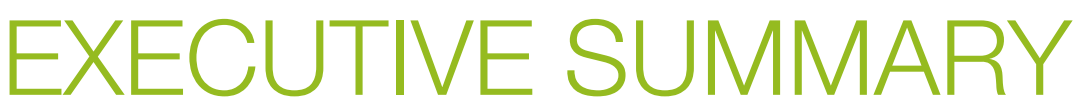

Biodiversity ${ }^{3}$ underpins the capacity of nature to function and deliver the ecosystem goods and services upon which the world depends. Yet, biodiversity is being lost at an alarming rate across the world's terrestrial, freshwater, and marine biomes, and current rates of extinction are about 1,000 times the likely background rate. Evidence is mounting that the loss of genes, species, and ecosystems - a crisis in its own right -- jeopardises the delivery of services provided by biodiversity to human communities. Reversing this trend requires slowing and eventually stopping the destruction, degradation, and overexploitation of natural habitats and, where appropriate, restoring these habitats.

One of the most effective ways to safeguard biodiversity is through conservation of sites that have high biodiversity value. Knowing, with precision, the location of those places that contribute significantly to the global persistence of biodiversity is therefore critical information for a wide range of end users across society, from national decision makers to private companies, as well as for use by international conventions and, ultimately, to direct conservation actions to halt further losses and address existing and emerging threats. The identification of Key Biodiversity Areas (KBAs), which are 'sites contributing significantly to the global persistence of biodiversity', is an important step towards more effective management of biodiversity.

Recognising that KBAs often include areas that are commercially productive (e.g. cultivated areas, managed forests, fisheries, mineral sites), it is important that businesses take action to influence how such areas are managed, either directly through their operations or indirectly through their supply chains. When operating in and around, or sourcing from, areas within KBAs (and/or within proximity of KBAs, potentially causing impacts), businesses can benefit from guidelines that facilitate their management decisions, in order to maintain the biodiversity values for which the KBA has been identified.

These Guidelines on Business and KBAs have been developed by the KBA Partners to support businesses in managing risk to biodiversity. They will be of use to business and certification scheme operators, financial institutions, civil society organisations, and public authorities in numerous situations, such as:

1. implementing the mitigation hierarchy for managing biodiversity risks associated with operations impacting biodiversity for which the KBA is important;

2. implementing international financial institutions' safeguards and environmental standards (see Box 1) for projects affecting biodiversity for which the KBA is important;

3. designing and reviewing sustainability standards, including for certification systems and project finance;

4. setting the permitting requirements for business operations having a potential impact on biodiversity for which the KBA is important;

5. guiding and informing engagements between civil society organisations and business entities; and

6. public reporting, including the Global Reporting Initiative (GRI) for sustainability reporting.

These Guidelines can be applied by businesses of all sizes and in all sectors, and by existing and new businesses having direct, indirect, and cumulative impacts on a KBA. They are applicable to the businesses' entire area of influence, as well as throughout the life cycle of the operation, from pre-feasibility to closure (and, where relevant, site rehabilitation). The Guidelines can also be integrated into responsible sourcing policies for goods and services, the production of which could have direct, indirect, and cumulative impacts on KBAs.

To support the implementation of the Guidelines, a section of the KBA website dedicated to Business and $K B A s$ provides additional information that can make each of the Guidelines more actionable. It includes links to existing resources and examples from field projects.

3 Convention on Biological Diversity (1992), Article 2 


\section{Box 1. International financial institutions' safeguard policies and environmental standards}

A number of safeguard policies and environmental standards have been established to inform decisions on allocation of resources for development and ensure sustainability in the lending and project-granting processes. These include safeguard policies from development banks, such as the World Bank Environmental and Social Framework, the Asian Development Bank (ADB) Safeguard Policy Statement, the Inter-American Development Bank (IDB) Environment and Safeguards Compliance Policy, and the European Bank for Reconstruction and Development (EBRD) Environmental and Social Policy, as well as the Organisation for Economic Co-operation and Development (OECD) Environmental and Social Due Diligence policy. There are also safeguards from private sector financial bodies, such as the Equator Principles Association, and the Sustainability Framework of the International Finance Corporation (IFC), which is part of the World Bank Group. IFC's Performance Standard 6 (PS6) on Biodiversity Conservation and Sustainable Management of Living Natural Resources is fast becoming a global benchmark for corporate best practice in relation to biodiversity. Critical habitats and natural habitats as defined in IFC PS6 are terms used by many other safeguard policies to describe habitats that are either especially sensitive to impacts or of high biodiversity significance. Because the criteria used to identify critical habitats and the KBA criteria are closely aligned, KBAs can be considered candidates to be classified as critical or natural habitats, and their use is specifically recommended in IFC PS6.

It is also critical to recognise that the business community can play a positive role in the conservation of KBAs, by supporting the World Database of Key Biodiversity Areas ${ }^{T M}$, sharing biodiversity data collected during the various stages of a project's operations, and financing the conservation of KBAs, either through philanthropic/ corporate social responsibility initiatives or offsets within KBAs for the residual impacts from other sites.

Finally, the effective management of a Key Biodiversity Area will only result from the joint efforts of actors that are directly and indirectly responsible for impacting the area. These actors include businesses with operations that directly or indirectly affect the area, as well as regulators who are responsible for setting land-use plans and performance requirements for the various users, local communities that are directly or indirectly conserving or affecting the area, and civil society organisations engaged in its conservation and development. The successful conservation of the biodiversity for which the KBA is important will depend on the participation, collaboration, and contributions of all these actors. 


\section{BUSINESS AND KBAs}

Risks and opportunities for biodiversity... Increasing consumption rates and population growth, combined with unsustainable production patterns, play a major role in the dramatic loss of biodiversity, driven by land-use change, climate change, invasive species, overexploitation of natural resources, and pollution. The reversal of the direct relationship between economic growth and biodiversity loss has been and is still at the centre of many public policies and conservation organisations' initiatives. Reversing this trend is even more important in areas that have been identified as critical for the global persistence of biodiversity. The paradigm in which business operations are the source of impacts can be turned around and transformed into a system in which business operations generate biodiversity conservation gains through their operations and funding.

....and for people. As the degradation of ecosystem services, underpinned by biodiversity, has a direct impact on people, the value of biodiversity for people should be at the centre of KBA conservation strategies. Much of the world's biodiversity can be found in the lands and territories of indigenous peoples and local communities, and has been and continues to be actively conserved by them. The loss of biodiversity has often disproportionately affected indigenous peoples and local communities across the world, with many of them dependent on natural ecosystems and the ecosystem services provided for their cultural, social, and economic well-being. Their cultures, identities, and physical survival as distinct peoples are sustained by lands and territories; in many cases habitat loss and reduced access to resources has led to scarcity of livelihood materials, decreasing food security, poor nutrition, ill health, severe hardship, and an increased risk of floods and soil instability. Indigenous and local communities play an essential role in conserving biodiversity, and in many cases community area-based conservation has proven to be more effective than conventional protected area management.

Business as a positive force for the conservation of KBAs. Businesses and other relevant actors can greatly contribute to the conservation of the biodiversity for which the KBA is important in a number of ways, including but not limited to:

- Making available to civil society and the scientific community the information gathered during their project and biodiversity management operations, including the data collected during the risk and impact assessments and the monitoring operations. This will be particularly important if the assessments conducted by the business show that the biodiversity values have already been degraded.

- $\quad$ Prioritising KBAs as the target of philanthropic and corporate social responsibility initiatives. This will generally ensure great visibility for the donors by providing a narrative based on an internationally recognised identification.

- $\quad$ Prioritising KBAs as recipients of offsets to compensate residual impacts in non-KBA sites, where this doesn't affect compensation for significant losses of other nationally or regionally important biodiversity or ecosystems. This approach could lead to investing in an area with an opportunity for greater conservation impact than the one affected by the project for which the offset is envisaged. This would provide the opportunity for businesses to invest in offsets that would achieve better conservation outcomes, effectively 'trading up' the net outcomes. 


\section{MORE ABOUT KBAs}

A strengthened approach to the conservation of global biodiversity. One of the most effective ways to safeguard biodiversity is through conservation of sites that have high biodiversity value. Knowing, with precision, the location of those places that contribute significantly to the global persistence of biodiversity is therefore critical information for a wide range of end users across society, from national decision makers and international conventions to private companies and local communities, ultimately, to direct conservation actions to halt further losses and address existing and emerging threats ${ }^{4}$. The identification of Key Biodiversity Areas, which are 'sites contributing significantly to the global persistence of biodiversity', is an important step towards more effective management of biodiversity.

A global standard for identifying sites of biodiversity importance. A Global Standard for the Identification of Key Biodiversity Areas, hereafter the 'KBA Standard', was adopted by IUCN in April 2016 and launched at the 2016 IUCN World Conservation Congress. The KBA Standard establishes a consultative, sciencebased process for site identification, founded on the consistent application of global criteria with quantitative thresholds that have been developed through an extensive consultation exercise spanning several years. It builds on existing approaches to the identification of important sites for biodiversity, such as Important Bird and Biodiversity Areas and Alliance for Zero Extinction sites. The KBA criteria encompass threatened biodiversity, geographically restricted biodiversity, ecological integrity, biological processes, and irreplaceability, and are applicable to species and ecosystems in terrestrial, inland water, and marine environments.

Some facts about KBAs. As in nature, diversity is what defines the areas identified to date as Key Biodiversity Areas. To illustrate this, consider:

- Total number of KBAs: 15,861

- Average size: 1,283.4 sq km

- Smallest: $0.01 \mathrm{sq} \mathrm{km}$ (There are several this size, mostly ponds or small breeding colonies.)

- Largest: 905,664 sq km (Proposed Central Pacific World Heritage Site, Kiribati)

- Mean percentage area of each KBA covered by protected areas: $46 \%$

- Percent of KBAs wholly covered (i.e. $>98 \%$ ) by protected areas: $25 \%$

Defining the boundaries of KBAs. Delineation is the process through which the boundaries of a KBA are drawn on a map. It is possible that a KBA may sometimes be smaller than the area of continuous habitat supporting a trigger species, for example if the habitat covers a protected area and also habitat outside, but for reasons of manageability, only the protected area portion is designated as a KBA. The KBA may also be larger than the area in which the trigger biodiversity element occurs, for example if that area is entirely within a larger protected area or some other management boundary.

The World Database of Key Biodiversity Areas ${ }^{\mathrm{TM}}$. The World Database of Key Biodiversity Areas ${ }^{\mathrm{TM}}$, managed by BirdLife International on behalf of the KBA Partnership, includes an interactive online map of KBAs with links to documentation for each site. In addition, KBA shapefiles are available on request for noncommercial use and are currently provided via the Integrated Biodiversity Assessment Tool (see Box 2). These sites will be re-assessed over time against the new KBA Standard. In addition, new sites will be identified as additional taxonomic groups and ecosystems are considered and all criteria in the KBA Standard are applied. 
Key Biodiversity Areas, protected areas, and conservation priorities. As clarified in the KBA Standard, KBAs are sites of importance for the global persistence of biodiversity. However, this does not imply that a specific conservation action, such as protected area designation, is required. KBAs may or may not receive formal protection, but they should be managed in ways that ensure the persistence of the biodiversity elements for which they are important. Such management decisions should be based on conservation priority-setting exercises, which typically combine data on biodiversity importance with available information on site vulnerability and management actions needed to safeguard the biodiversity for which the site is important.

\section{Box 2. The Integrated Biodiversity Assessment Tool (IBAT)}

For commercial use, the data in the World Database of Key Biodiversity Areas ${ }^{\mathrm{TM}}$ can be accessed through the Integrated Biodiversity Assessment Tool (IBAT) at www.ibat-alliance.org. IBAT is a partnership between BirdLife International, Conservation International, IUCN, and the UN Environment World Conservation Monitoring Centre (UNEP-WCMC). It is an online tool designed to facilitate access to currently identified KBAs, the World Database on Protected Areas, and the IUCN Red List of Threatened Species ${ }^{\mathrm{TM}}$, combined with other relevant ecological datasets. All information can be accessed through a simple user interface that allows users to display dynamic georeferenced maps and submit specific queries. IBAT helps businesses incorporate biodiversity considerations into key project planning and management decisions, including screening potential investments, siting an operation in a given region, developing action plans to manage biodiversity impacts, assessing risks associated with potential sourcing regions, and reporting on corporate biodiversity performance. 


\section{GUIDELINES FOR BUSINESS ACTIVITIES}

Applicability. The Guidelines can be applied by businesses of all sizes and in all sectors, and by existing and new business operations having, and potentially having, direct, indirect, and cumulative impacts on a Key Biodiversity Area. They are designed assuming their application to the businesses' area of influence (see Box 3) and to the entire life cycle of the operation, from pre-feasibility to closure (and, where relevant, site rehabilitation). The Guidelines can also be integrated into responsible sourcing policies for goods and services, the production of which could have direct, indirect, and cumulative impacts on KBAs.

\section{Box 3. Area of Influence}

A business operation's area of influence encompasses, as appropriate:

- The area likely to be affected by: (i) the project and the business's activities and facilities that are directly owned, operated, or managed (including by contractors) and that are a component of the project; (ii) impacts from unplanned but predictable developments caused by the project that may occur later or at a different location; or (iii) indirect project impacts on biodiversity or on ecosystem services upon which affected communities' livelihoods are dependent.

- Associated facilities, which are facilities that are not funded as part of the project, that would not have been constructed or expanded if the project did not exist, and without which the project would not be viable.

- Cumulative impacts that result from the incremental impact, on areas or resources used or directly impacted by the project, from other existing, planned, or reasonably defined developments at the time the risks and impacts identification process is conducted.

Source: International Finance Corporation's Policy on Environmental and Social Sustainability (2012) 
Conditions for successful implementation. A number of factors can contribute to the successful implementation of the Guidelines, including:

- The various stages of the mitigation hierarchy and these Guidelines are designed and implemented in the context of a changing environment, in particular in light of the effects of climate change.

- KBAs are subject to different governance models. It is vital that these Guidelines are contextualised appropriately in each situation, taking into consideration formal and informal governance arrangements, land and natural resource tenure and rights, and the needs and rights of local communities and/or indigenous peoples living in or around the KBA.

- If a KBA is designated as a protected area, when implementing the mitigation hierarchy, the business takes into consideration zoning, management plans, and legal restrictions set by the relevant authorities.

- The establishment of an inclusive and transparent stakeholder and right-holder engagement process (including, for example, representatives of national, regional, and local government; indigenous peoples; local communities; and other elements of civil society) in planning and decision making is recommended. International best practices for stakeholder and right-holder engagement, including a rights-based approach and Free, Prior, and Informed Consent (FPIC) for engaging with indigenous and traditional peoples and local communities, are implemented as early as possible in the project cycle and follow recognised best practices.

- Where indigenous peoples and local communities live in or near a KBA, their engagement in restoration and offset activities is prioritised, not only to increase the likelihood of successful and socially acceptable remediation results, but also to provide important socio-economic benefits to communities.

- Where possible, indigenous and local knowledge is included alongside the sciences, as complementary systems of knowledge for achieving a fuller and richer understanding of biodiversity values, functioning, status, and trends, as well as the consequences of its loss at different scales. For example, traditional knowledge can provide many contributions to ecological restoration, including through the construction of reference ecosystems (particularly when historical information is not available), input into species and site selection for restoration activities, knowledge of historical land-management practices, input into management of invasive species, and post-restoration monitoring.

Access to data on Key Biodiversity Areas for commercial use. All commercial users of these Guidelines should access data on Key Biodiversity Areas through IBAT for Business. Commercial use means any use by, on behalf of, or to inform or assist the activities of, a commercial entity (an entity that operates 'for profit'), or use by any individual or non-profit entity for the purposes of revenue generation.

A web site to support the implementation of the Guidelines. To support the implementation of the Guidelines, a section of the KBA website dedicated to Business and KBAs provides additional information that can make each of the Guidelines more actionable. It includes links to existing resources and examples from field projects. A Questions \& Answers section also supports quick access to common questions and concerns. The information will be regularly updated and supplemented by new examples from business in using the guidelines, building in particular on the experience acquired by the KBA Partners in using the Guidelines. 


\section{Project-level Guidelines}

The KBA Partners recommend the application of the mitigation hierarchy (see Box 4) to any project with direct, indirect, or cumulative impacts on biodiversity. Furthermore, to support the effective implementation of the various steps in the mitigation hierarchy, the KBA Partners recommend the adoption of additional measures specifically aimed at ensuring the global persistence of biodiversity in line with the purpose of the KBA Standard, which is to locate and highlight sites that make significant contributions to the global persistence of biodiversity.

\section{Box 4. The Mitigation Hierarchy}

The mitigation hierarchy is a framework for addressing project impacts, defined as:

1. Avoidance: measures taken to avoid creating impacts from the outset, such as careful spatial or temporal placement of elements of infrastructure in order to completely avoid impacts on certain components of biodiversity.

2. Minimisation: measures taken to reduce the duration, intensity, and/or extent of impacts, including, as appropriate, direct, indirect, and cumulative impacts (including from climate change), that cannot be completely avoided, as far as is practically feasible.

3. Rehabilitation/restoration: measures taken to rehabilitate degraded ecosystems or restore cleared ecosystems following exposure to impacts that cannot be completely avoided and/or minimised.

4. Offset: measures taken to compensate for any residual significant, adverse impacts that cannot be avoided, minimised, and/or rehabilitated or restored, in order to achieve no net loss or a net gain of biodiversity. Offsets can take the form of positive management interventions, such as restoration of degraded habitat or arrested degradation, or averted risk through protection of areas where there is imminent or projected loss of biodiversity. Offsets should only be considered after following the first three steps of the mitigation hierarchy to further reduce residual impacts.

Source: Glossary (2012), Business and Biodiversity Offset Programme

Project biodiversity baseline. Potential residual impacts of a project are determined against a baseline representing the pre-project condition of the biodiversity element(s) for which the site qualifies as a KBA (including the supporting ecological context).

How can the World Database of Key Biodiversity Areas ${ }^{\mathrm{TM}}$ help? The World Database of Key Biodiversity Areas ${ }^{\mathrm{TM}}$ can be used to identify the trigger biodiversity element(s) that need to be assessed as part of the baseline studies. In addition, information on existing threats would also help in completing the study. 
Priority to avoidance. All forms of avoidance are prioritised (see Box 4), including not proceeding with project development where it is likely that negative impacts on the biodiversity elements triggering the identification of the KBA will occur, or relocating the project to other sites, prioritising, where relevant, already degraded areas. As established by IUCN Members, certain activities should be avoided in KBAs, including environmentally damaging industrial activities and infrastructure (WCC-2016-Rec-102), oil palm plantations (WCC-2016-Res-061), and activities that would lead to the loss of primary forest (WCC-2016-Res-045).

How can the World Database of Key Biodiversity Areas ${ }^{\mathrm{TM}}$ help?

The identification of sensitive areas during screening processes and baseline surveys is of critical importance. The World Database of Key Biodiversity Areas ${ }^{\mathrm{TM}}$ can be used to show where existing or future project sites, operations, and supply chains are located in relation to KBAs. The World Database of Key Biodiversity Areas ${ }^{\mathrm{TM}}$ can also help indicate the relative importance of the site for the persistence of the trigger elements (for example, if the site is home to a high percentage of the global population of a species). Furthermore, measures and plans may be designed to minimise impacts on KBAs in or near a concession or across a supply chain by focusing on specific biodiversity elements for which that KBA was identified.

Implementation of early minimisation. For the biodiversity element(s) for which the KBA has been identified, minimisation measures are adopted as early as possible, even before the disturbance occurs.

How can the World Database of Key Biodiversity Areas ${ }^{\mathrm{TM}}$ help? The World Database of Key Biodiversity Areas ${ }^{\mathrm{TM}}$ can help identify existing threats to the biodiversity trigger elements that could be worsened by the project's impacts. Furthermore, information on the behaviour and ecology of the trigger elements can help identify effective minimisation measures.

Limits to impact restoration. Where it is not possible to avoid and minimise all impacts, the feasibility of ecological restoration is determined, with particular consideration given to the biodiversity elements for which the site is identified as a KBA (as documented in the World Database of Key Biodiversity Areas ${ }^{\mathrm{TM}}$ ), and restoration is conducted where it is ecologically feasible. A precautionary approach to ecological restoration should be applied, particularly when predicting restoration success as part of residual impact estimates. Empirical expert advice and best available scientific evidence is essential to determine the feasibility and effectiveness of restoration plans. Furthermore, it is recommended that the limits to offsets established by the IUCN Policy on Biodiversity Offsets (see Box 5) should also apply to the restoration of the project's impact, and that the restoration potential, including in the light of climate change, is demonstrated before project activities commence.

How can the World Database of Key Biodiversity Areas ${ }^{\mathrm{TM}}$ help? The World Database of Key Biodiversity Areas ${ }^{\mathrm{TM}}$ can be used to identify which habitat types occur in the KBA, to help focus additional research on restoration success for those habitat types in other KBAs and sites. 
Limits to biodiversity offsets. Offsets to address unavoidable residual impacts in KBAs should follow the IUCN Policy on Biodiversity Offsets. In addition to the limits to biodiversity offsets articulated in the IUCN Policy (see Box 5), and given the importance of KBAs for the global persistence of biodiversity, the following additional guidelines are suggested when the residual impacts affect the biodiversity element(s) triggering the identification of the KBA:

- Offsets for residual impacts in KBAs should achieve Net Gain on the trigger element(s) affected by the project, such that the element(s) is highly likely to persist in the light of climate change and governance instability.

- Offset gains should be achieved before impacts occur, or, where offset gains may take time to achieve, offsets should be initiated with clear financing before impacts occur.

- Offsets should not be used where residual impacts on biodiversity are likely to lead to a site no longer meeting the KBA criteria for any of its trigger elements, except in exceptional circumstances when the offset will demonstrably generate significant gains in the global persistence of each of these elements that exceeds the loss caused by the residual impact.

- The development and offset should both have obtained the free, prior, and informed consent of any impacted local communities.

How can the World Database of Key Biodiversity Areas $^{\mathrm{TM}}$ help?

The World Database of Key Biodiversity Areas can help in the

identification of potential offsets by offering information on the

population size or geographic extent of the trigger elements at

the impacted KBA and other KBAs, and the threats facing those

elements.

\section{Box 5. Limits to biodiversity offsets, according to the IUCN Policy on} Biodiversity Offsets

The IUCN Policy on Biodiversity Offsets states that 'In certain circumstances residual impacts on biodiversity (after completing the avoidance, minimisation and rehabilitation steps of the mitigation hierarchy) cannot be offset. Additionally, there are some components of biodiversity for which impacts could theoretically be offset, but with a high risk of failure. Under these circumstances, biodiversity offsets are not appropriate, and this means that the project as designed should not proceed.'

The policy then lists the minimum circumstances in which offsets should not be considered. Particularly relevant to the case of KBAs are situations where:

- $\quad$ impacts are likely to lead to a high risk of driving one or more previously non-threatened species and/or ecosystems into the IUCN Red List Categories of Vulnerable, Endangered, Critically Endangered, Extinct in the Wild, or Extinct; or driving one or more previously threatened species and/or ecosystems into IUCN Red List Categories of higher threat; or

- the values that will be lost are specific to a particular place, and therefore cannot be found elsewhere and adequately protected or re-created. 
Biodiversity impact monitoring. In implementing the monitoring plan, it is crucial that:

- the biodiversity elements that have triggered the KBA identification are included in the monitoring plan (even if these elements have not been highlighted as areas of concern in the impact assessment);

- the business monitoring system is aligned with and contributes to the KBA-wide monitoring efforts, if present, and, where KBAs are in or near indigenous peoples' or local communities' lands and territories, community-based monitoring of KBAs is supported;

- the data collected during the monitoring activities are made available to the KBA Partners and included in the KBA database, consistent with the Red List Policy on sensitive data access; and

- $\quad$ the results of the monitoring are publicly disclosed, with considerations for confidential information.

How can the World Database of Key Biodiversity Areas ${ }^{\mathrm{TM}}$ help?

The World Database of Key Biodiversity Areas ${ }^{\mathrm{TM}}$ can be used to

identify those biodiversity elements, that should be regularly monitored

and provides information on the population size or geographic extent

of trigger elements prior to project impacts.

Long-term financing of the mitigation measures. Sustainable and sufficient financing for the implementation of all the mitigation measures ${ }^{5}$ resulting from business operations in KBAs throughout the project life cycle is secured from the outset of the operations.

Responsibilities in case of divestment. The ongoing actions and commitments are passed on to new owners in case of divestment.

Participation and consultation. Those institutions, organisations, communities, and people involved in the identification of the KBA should be consulted. Furthermore, decision-making processes should be transparent.

Responsibility for existing operations. Additional conservation actions that will lead to conservation benefits for the biodiversity element(s) triggering the KBA identification should be implemented to make up for the impacts generated by operations that started before the identification of the KBA or before these guidelines were issued. Impacts linked to extensions of the project and future operations should be managed according to the mitigation hierarchy and Guidelines 1 to 9.

5 For specific recommendations related to financing of offsets, see the IUCN Offset Policy. https://portals.iucn.org/library/sites/library/files/resrecfiles/ WCC_2016_RES_059_EN.pdf 


\section{Corporate-level Guidelines}

The KBA Partners recommend the following additional Guidelines at the corporate/group level:

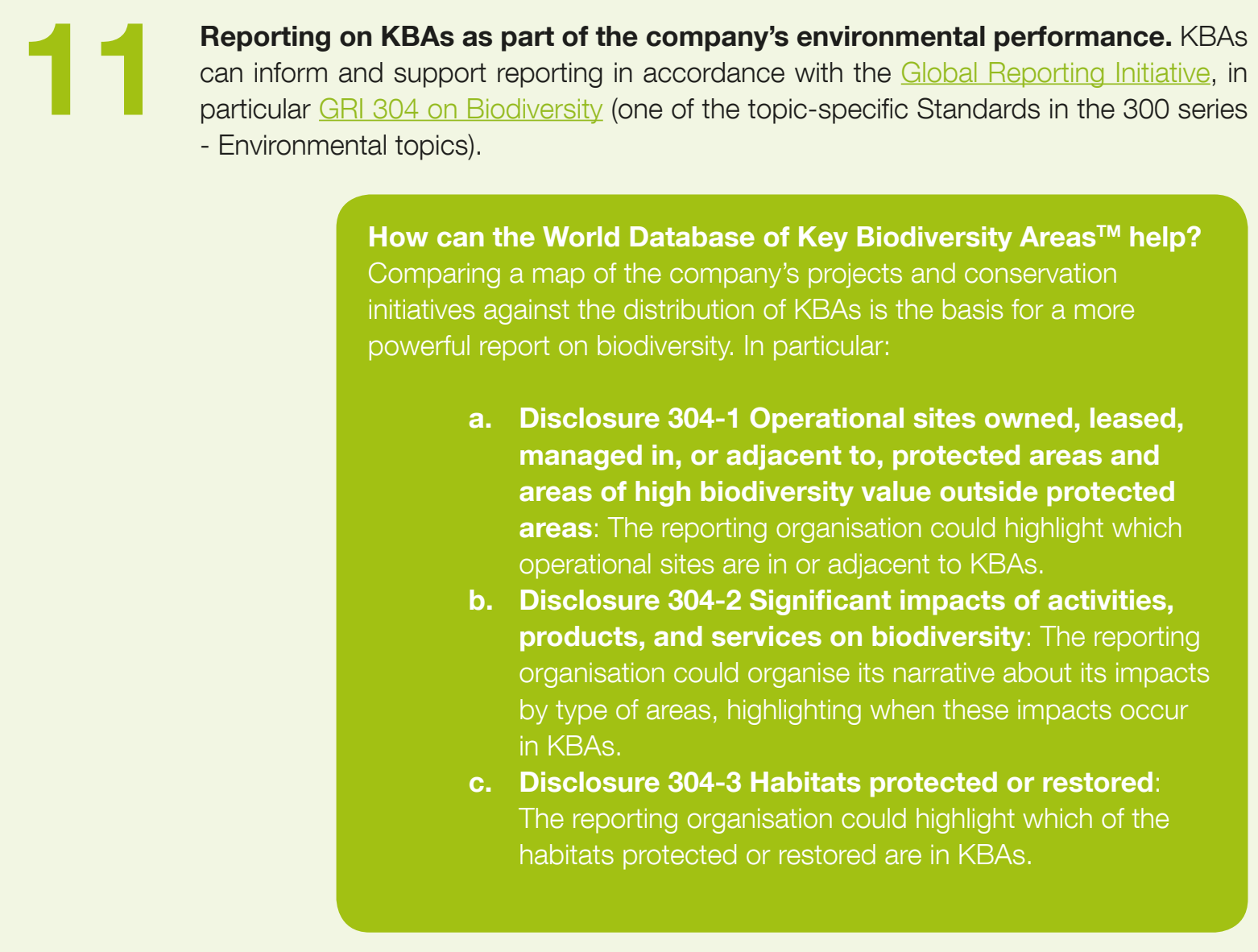

12

Additional conservation actions. Often, businesses seek to invest in conservation interventions for features above and beyond those impacted by their own activities. This could be because there is geographic proximity between the company and the KBA, for example, or some connection between the company and the biodiversity elements for which a given KBA is important. Actions to safeguard the biodiversity for which a given KBA is important therefore provide a highly desirable focus for such corporate social responsibility.

How can the World Database of Key Biodiversity Areas ${ }^{\mathrm{TM}}$ help? The World Database of Key Biodiversity Areas ${ }^{\mathrm{TM}}$ provides spatial data on the location of KBAs (which could be compared to, for instance, the locations of a business's headquarters, key points in its supply chain, or its major markets) and tabular data on the biodiversity for which the site is important (which could be searched for, say, species represented in a business's name or logo). Once KBAs where a business is interested in focusing such corporate social responsibility have been identified, the documentation of conservation actions 'ongoing' or 'required' at each of these KBAs can guide what kind of actions would be most appropriate for such investment. 
KBAs as targets for offsetting impacts elsewhere. Selecting KBAs as recipients of offsets to compensate residual impacts in non-KBA sites could possibly lead to investing in an area with an opportunity for greater conservation impact than the one affected by the project for which the offset is envisaged. This would open an opportunity for the business to invest in offsets that would achieve better conservation outcomes, effectively 'trading up' the net outcomes. However, such 'trading up' should not cross national boundaries where doing so is legally, politically, or socially unacceptable.

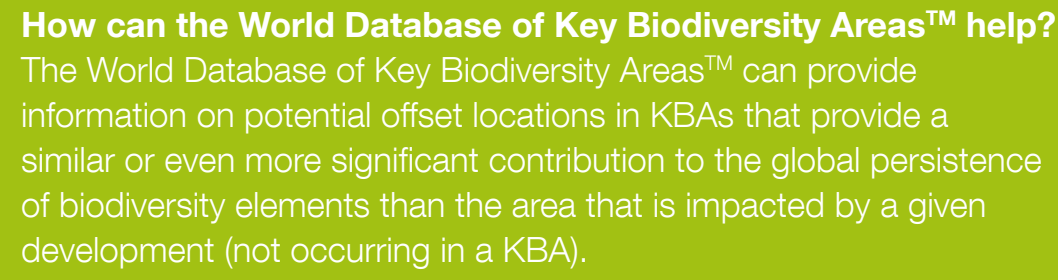

Sharing biodiversity data. The business can play a critical role in supporting the World Database of Key Biodiversity Areas ${ }^{\mathrm{TM}}$ by sharing relevant data with the KBA Partners, consistent with the Red List Policy on sensitive data access. In particular, the data collected during Environmental Impact Assessment processes, baseline studies, and monitoring activities can add great richness to the database.

Compliance with certification schemes and financial institutions' safeguard policies. Reviewing the presence of a business' operations in KBAs will help assess compliance with voluntary sustainability standards and financial institutions' safeguard policies, which often require consideration of impacts on areas of high biodiversity value, such as KBAs. 


\section{RESOURCES}

A Cross-Sector Guide for Implementing the Mitigation Hierarchy (2015), Cross Sector Biodiversity Initiative. http://www.csbi.org. uk/wp-content/uploads/2015/09/CSBI-Mitigation-Hierarchy-Guide-Sept-2015-1.pdf

BBOP Standard on Biodiversity Offsets and associated material.

http://bbop.forest-trends.org/pages/guidelines

Biodiversity for Business: A guide to using knowledge products delivered through IUCN (2014), IUCN.

https://portals.iucn.org/library/sites/library/files/documents/2014-004.pdf

Biodiversity offsets technical study paper (2014), IUCN.

https://portals.iucn.org/library/sites/library/files/documents/2014-044.pdf

CSBI Timeline Tool (2013), Cross Sector Biodiversity Initiative.

http://www.csbi.org.uk/wp-content/uploads/2015/12/csbi timeline tool jan 2014.pdf

Free, Prior and Informed Consent Guide for RSPO members (2015), RSPO.

http://www.rspo.org/news-and-events/announcements/free-prior-and-informed-consent-guide-for-rspo-

members-2015-endorsed\#

A Global Standard for the Identification of Key Biodiversity Areas (2016), IUCN.

https://portals.iucn.org/union/sites/union/files/doc/a global standard for the identification of key

biodiversity areas final web.pdf

Good Practices for the Collection of Biodiversity Baseline Data (2015), Cross Sector Biodiversity Initiative. http://www.csbi.org.uk/wp-content/uploads/2015/07/Biodiversity Baseline JULY 4a-2.pdf

Guidelines for the appropriate use of the IUCN Red List for business (2016), IUCN.

https://cmsdocs.s3.amazonaws.com/keydocuments/Guidelines_for_Appropriate_Use_of_IUCN_Red_List_ for Business ver1.pdf

How to do. Seeking free, prior and informed consent in IFAD investment projects (2015), IFAD.

https://www.ifad.org/documents/10180/beec86e1-270d-45a1-8786-4b749c9db733

IUCN Policy on Biodiversity Offsets (2016), IUCN.

https://portals.iucn.org/library/sites/library/files/resrecfiles/WCC 2016 RES 059 EN.pdf

IUCN Review protocol for biodiversity net gain (2017), IUCN.

https://portals.iucn.org/library/sites/library/files/documents/2017-033 0.pdf

Performance Standard 6 Biodiversity Conservation and Sustainable Management of Living Natural Resources (2012), International Finance Corporation (IFC).

http://www.ifc.org/wps/wcm/connect/bffOa28049a790d6b835faa8c6a8312a/PS6 English 2012. pdf?MOD=AJPERES

Strengthening implementation of the mitigation hierarchy: managing biodiversity risk for conservation gains (2015), Cambridge Conservation Initiative - Collaborative Fund Project Report compiled by: BirdLife International, UNEP-WCMC, RSPB, FFI, and the University of Cambridge.

http://www.birdlife.org/sites/default/files/attachments/cci report - managing risk for conservation gains final - june 9th 2015.pdf

Technical conditions for positive outcomes from biodiversity offsets: an input paper for the IUCN Technical Study Group on Biodiversity Offsets (2014), IUCN.

https://portals.iucn.org/library/sites/library/files/documents/2014-027.pdf 



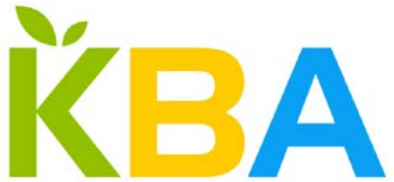

KEY BIODIVERSITY AREAS

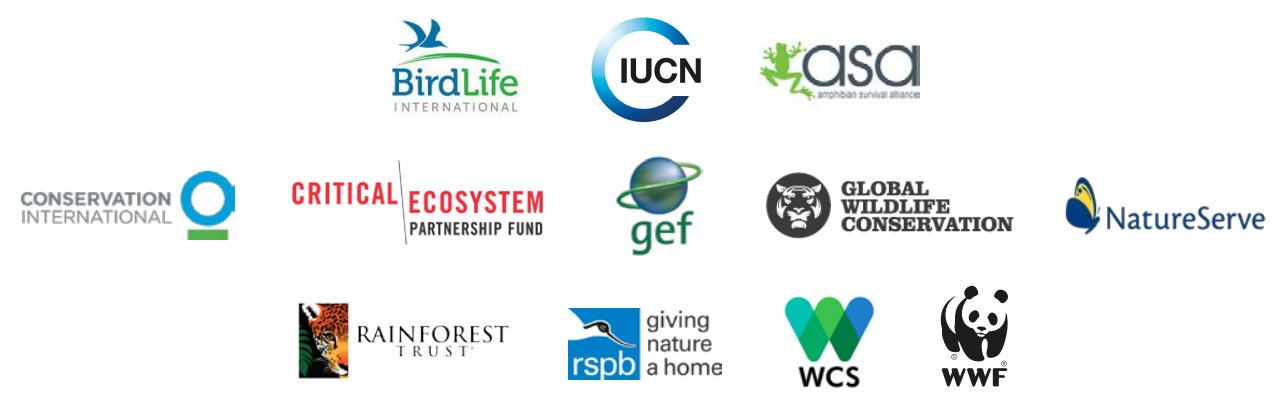

